\title{
LOS NICOLÁS ZAMALVIDES *
}

Edmundo Motta Zamalloa ${ }^{1}$

Mi nombre es Nicolás Zamalvides. Nací en la primavera de 1975 cuando se estaba poniendo el sol y María Cristina se corría hacia la puerta. Mi madre solía decir que tuvo que morder las sábanas para no gritar por los dolores del parto que se aproximaba. Pero a pesar de tales dolores y los ajetreos de la comadrita Estefa Moncada que repartía órdenes para cuando llegara el momento, mi madre pudo fijarse en el cono de luz que entraba por un hueco del tejado y atravesando de lado la penumbra de la habitación alumbró el paso de María Cristina, la mejor ponedora que tuvimos siempre en el solar de Pumanchy, que corría bajando el pico junto al lecho de la parturienta. Nunca se cansaba de recordármelo. Naciste cuando María Cristina buscaba la luz.

Crecí rodeado de bulliciosas ponedoras que picoteaban el maíz en el solar y cerca de un cura a quien años después serví de monaguillo los domingos. No sabía que existían o existieron otros Nicolás Zamalvides que vivieron en circunstancias parecidas y que murieron de la misma muerte, cosa que sabré seguramente cuando mellegue la hora de la verdad.

La primera vez que me revelaron de la existencia de otro Nicolás Zamalvides fue un atardecer del mes de mayo cuando pasó por el solar el cura Octavio Casas montado en un hermoso y descansado bayo.

Yo tenía bajo el brazo a Cristina, hija de María Cristina, mi reciente ponedora favorita. Era mi preferida porque ponía huevos todos los días para mí solo. Me gustaba ponerle maíz en el pico, y sentir en los dedos sus picotazos que se volvían violentos cuando la arredraba el hambre. Pero si estaba satisfecha, daba gusto cargarla y sentir su cuerpo caliente y su respiración agitada, cloqueaba como si ella quisiera mostrarse contenta y me daba con el pico suaves toques en los dedos. Cuando tenía sed sumergía la cabecita en un pequeño cuenco de madera, y luego empinaba para tragar el agua. Una y otra vez hasta que sacudía la cresta señal de que estaba satisfecha. A mi me agradaba jugar con ella. La hacía correr por el perímetro del solar, saltar pequeños obstáculos, o hacerla marear soltando granos de maíz ya a un lado, ya al otro, y enseguida la alzaba y apretaba contra mi pecho. Estaba en eso cuando me di cuenta que el

\footnotetext{
${ }^{1}$ Docente Principal de la Universidad Nacional Jorge Basadre Grohnam. Tacna-Perú.

Correoelectrónico:parmenides5ac@ihotmail.com
}

* Del inédito: Caballeros de paso. 
cura Octavio Casas nos estaba observando con extrema curiosidad. Había sobreparado su caballo tras el muro del pasacalle.

--Mismo Nicolás Zamalvides -dijo, dirigiéndose a mi madre.

A un tiempo movió los ojos en la dirección de las montañas azules del sur, en cuyos flancos los abismos no tienen límite.

Yo estaba en la luna. Me cayó como un puñete en la cara saber que otro Nicolás Zamalvides, como yo, vivía allá por los flancos donde se encadenaban los cerros azules que miraba el cura, y quizá al igual que yo tenía su ponedora preferida. ¿Será verdad? Dudaba. Conociendo al cura, quizá una más de las bromas que se gastaba cada vez que salía en el bayo a dar un paseo por los campos y volvía con las alforjas reventando de maíz. Aunque más parecía un chacarero por su modo de hablar y vestir, y ese sombrero de paja que caía sobre su cabeza como un paraguas, el cura Octavio Casas era el único de los pocos que pasaron por Pumanchy en llevar agua bendita en una botella de cerveza para bendecir el trabajo en las chacras. Tenía que ser Octavio Casas, decía la gente, un hijo de este pueblo, al igual que los choclos de Layme o las papas de Aticio. Los domingos antes de celebrar misa se armaba de valor y escuchaba sentado no encima del bayo sino en el confesonario de la iglesia, con la oreja pegada a la rejilla los pecados de las mujeres, entre las que iba mi tía Evita Ávila. Ella se postraba de rodillas, la cabeza envuelta con velo negro, y se echaba a llorar mientras se sacaba del alma cada una de sus culpas en voz muy bajita y entrecortada. Después se movía a la banca del baptisterio y rezaba las oraciones de la penitencia. De las cosas que se enteraba el cura. Yo estaba intrigado por saber los pecados de mi tía Evita Ávila y varias veces estuve tentado de preguntarle al cura, pero me daba vergüenza y callaba. Siempre tuve curiosidad por las cosas que ella hacía, porque era chiquita y tetona, ojos grandes y brillantes como el capulí de retoño, la nariz delgada y curvada como el pico de una gallina, piernas gruesas pero menudas y las manos pequeñas que terminaban en uñas con colorete. Eso sí andaba animado con la idea de que más tarde cuando fuera grande quería ser cura y no policía, ni preceptor, y menos domador de potros.

Antes de continuar su itinerario el cura se apeó del bayo, revolvió mi cabello y tocó con un dedo la cabeza de Cristina oprimida bajo mi brazo. Yo sentí como si fuera la mano de un hermano mayor.

--Oye, Nico, así que te gustan las ponedoras.

En una pequeña canasta mi madre contó no sé cuántos huevos que se los dio al cura. Ella estaba contenta porque había sido una buena cosecha y como cada vez que estaba contenta recordaba a mi hermana ausente, a mi padre viajero, a mis tíos que andaban por cualquier lado de la tierra, acaso pensando que podía enviarles una parte de la cosecha.

Había sido un día arduo por el trabajo de cortar y apilar el maíz y por el calor de los mil infiernos que hacía en el pueblo.

Junto a Cristina habían cuarenta ponedoras que andaban picoteando en el solar el día entero. Estaban tan gordas que parecían unas marranas. El maíz no se acababa nunca y yo tenía que repartir agua en vasijas de arcilla para que las ponedoras no se murieran de sed. Cuando el sol se echaba a perder, marchaban en fila hacia el dormidero, un tronco de eucalipto extendido entre la pared y el fogón de la cocina. Estoy seguro que no faltaba ninguna y, sin embargo las contaba, uno dos tres cuatro.... hasta que hacían cuarentaiuno. Para estar seguro que no me había equivocado 
las volvía a contar al revés. A parte de las ponedoras había gallinas corrientes, gallos y pollitos, en cantidad. Mi madre decía que teníamos bastante pero no tantos como los que tenía mi tío Nicolás Zamalvides en su pueblo de Mollebamba.

Cuando mi madre dijo que Nicolás Zamalvides era su medio hermano, pensé que era un enano. Tal vez un hombrecito de metro y pico de estatura, cosa que por lo demás no me parecía extraño sabiendo que en Pumanchy los hombres eran retacos y las mujeres chatas, un poco más subidas de porte que mi tía Evita, pero chatas. Tanto que los forasteros decían que donde veían un sombrero con toda seguridad debajo respiraba un pumanchino; si se juntaban en una asamblea en la plaza del pueblo, sólo veían un montón de sombreros; si acaso se encontraban en el camino con un caballo aparejado, pensaban que el caballo iba solo, y el jinete en la alforja. El propio cura Octavio Casas era chato y regordete como el gallo que andaba detrás de las ponedoras. Así debía ser mi tío Nicolás Zamalvides, pensaba yo.

--No-rió mi madre--, es mi medio hermano porque somos hermanos sólo por padre.

Nicolás Zamalvides era hermano de mi madre, por el lado de mi abuelo Emigdio. Mi abuelo tuvo diez hijos en mujeres distintas. Como era arriero tuvo mujeres en cada pueblo de la sierra que visitaba, y en cada una de ellas puso su semilla.

Mi madre y su medio hermano se conocieron cuando ya eran jóvenes. Mi madre nació en Pachaconas pero vivía en Antabamba hasta el día en que mi padre se la robó en la grupa de su caballo. Mi tío Nicolás nació en Silco pero vivía en Mollebamba. Mi tía Emilia vino al mundo en Huancaray pero vivía en Chalhuanca. Mientras pudo mi abuelo Emigdio iba de un pueblo a otro tras una recua de mulas car-

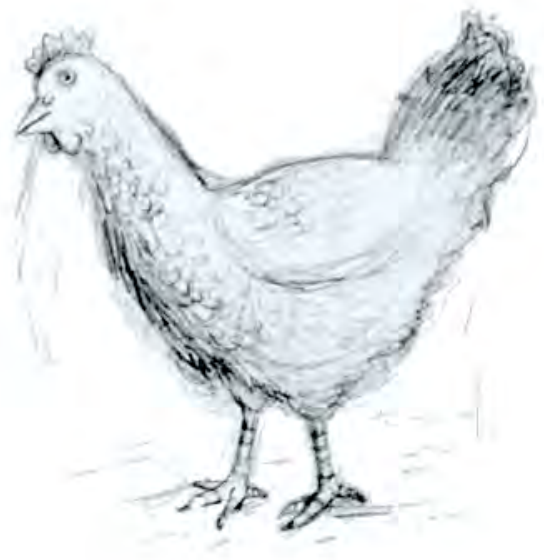
gadas de lana cuando bajaba de la sierra a la costa, y retornaba de los llanos cálidos con víveres y telas para los señores de la sierra. Decía mi madre que supo por mi tío Nicolás que tenía un hermano negro habido en una mulata de Nazca y que vivía en el puerto de Pisco dedicado a recoger mariscos.

Para no seguir el mismo camino que mi abuelo Emigdio, mi tío Nicolás se había plantado en Mollebamba y dedicado a la agricultura. Se había casado joven y ahora tenía tantos hijos como los tuvo mi abuelo Emigdio, pero todos en una sola mujer.

En uno de mis viajes pasé por el pueblo de Mollebamba. Si no recuerdo mal, era el año 1993. Caía el crepúsculo sobre los tejados del pueblo cuando el carro se detuvo en la plaza. Me acuerdo el momento en que el carro ingresó al pueblo y el ruido del motor espantó a una enorme cantidad de gallinas. Una mujer y tres chicas, de unos quince a diecisiete años de edad, se afanaban en juntarlas para que el carro no las aplastara.

--Son las gallinas de Nicolás Zamalvides - dijo el chofer.

Enseguida el chofer saludó a un hombre de regular estatura, alto si uno lo comparaba con los hombres de Pumanchy, gordo y bonachón. Iba apurado detrás de las 
muchachas. No se detuvo cuando lo saludé, "Tío Nicolás, te manda saludos tu hermana Julia". Se limitó a mirarme como un sordo y continuó su camino. Un bigote sucio y recargado pesaba sobre sus labios.

Antes de proseguir viaje, los pasajeros cenamos esa noche en la pensión del pueblo un buen caldo de gallina con abundante picado de cebolla china y trozos de ají tostados.

La segunda vez que mi madre mencionó a su medio hermano fue el atardecer de un verano. Acababa de llover a cántaros y, tras la lluvia, el sol había vuelto a salir. Un arco de siete colores se extendió entre la quebrada del río Tunabamba y la cadena de montañas azules que se deslizaban al sur. Nada era más hermoso que esa tarde, y, sin embargo, latía sobre las montañas un juego de sombras enigmáticas. Mi madre tuvo un presentimiento atroz y a causa de él entristeció aquél día. Unos meses después me dijo que mi tío Nicolás Zamalvides había fallecido de un ataque al corazón. Y sus doce hijos se habían dispersado por los pueblos de la provincia, llevándose cada quien un lote de gallinas como única herencia de su padre.

Con el correr de los años mi deseo de ser cura se había acentuado. Quizá es cierto que los hijos van en sentido contrario a los deseos del padre. Y siendo mi padre un declarado detractor de los curas, que era disipado en comer, beber y fumar, que iba al templo a escuchar los sermones del padre Octavio Casas solo porque lo llevaba mi madre arrastrándolo del brazo, era de esperar que los hijos, como quizá ocurría por lo menos conmigo, quería ser precisamente cura. Después de asistir al padre Octavio Casas de niño en el pueblo, anduve en la ciudad con monjas que me trataban como a una mascota; si me preguntaban qué me gustaría ser de grande mi respuesta inequívoca era, "cura". Ellas celebraban mis ilusiones con estrépito, se alegraban como niñas, y de premio doblaban mi ración de chancay; aunque luego se ponían serias, me miraban a los ojos hasta el fondo del alma y terminaban diciendo que para ser cura debía ocurrir algo más importante que la decisión de uno mismo, y ese algo era la voluntad del Todopoderoso. Porque habían de los indecisos que se engañaban a sí mismos, tan pronto se hacían curas y tiempo después enterraban su vocación colgando el hábito, y tenían mujer e hijos como un hombre cualquiera. Para que eso no ocurriera conmigo lo mejor que podía hacer era esperar hasta el momento en que el Señor tuviera compasión de mi paciencia y me llamara. En algún momento, cuando menos lo esperabas, de noche mientras dormías, de día aunque estuvieras jugando, el Señor se manifestaba. Te tocaba tu espíritu y llamaba.

Me había hecho joven y seguía esperando el llamado del Señor. Estudiaba en una universidad y por las tardes acudía al Seminario de San Jerónimo a hurgar en su biblioteca. Cuando recorría sus silenciosos pasillos sentía envidia por los seminaristas que vivían allí preparándose para ser ordenados como ministros de Dios; el espíritu se regocijaba en la capilla inundada de luz celeste por los cristales azulados de la bóveda o en los jardines rebosantes de rosas y gladiolos que daban el toque final para sentirse en el paraíso. A más de eso tenían una amplia biblioteca con mesas de lectura trapezoidales. No me cabía la menor duda, ese era el lugar perfecto para mí. Estaba decidido, apenas sintiera el llamado del Señor me mudaría inmediatamente al Seminario. Pasaban los años, y en vez de oír la voz del Señor, quien me llamó fue una muchacha de ojos pardos y soñadores. Y tiempo después me llamó la que sería mi 
mujer,

Mientras aguardaba el día en que el Señor se manifestara, allá en la biblioteca del Seminario de San Jerónimo, abrí un viejo periódico del siglo XIX, del año 1893 para ser precisos, llamado La Bolsa, y en la página policial leí una nota acerca de la muerte de un personaje cuyo nombre me sobrecogió tanto que por poco me sentí como un resucitado. Se llamaba Nicolás Zamalvides, nada menos, de quien decían era un honorable cargador, conocido y querido en el mercado San Camilo.

Según el cronista, Nicolás Zamalvides vivía en un hotel que pagaba con sus ingresos diarios. Al terminar su jornada de trabajo descansaba un rato, se mudaba de ropa y salía vestido con terno y corbata, como el caballero que era, pero sin zapatos, a dar una caminata por los alrededores. En la tarde se encontraba con sus amigos y dejaba correr el tiempo charlando sobre mujeres en una cantina de la calle Rosada mientras amagaban la sed con unas botellas de cerveza.

Después se retiraba a su hotel andando en zigzag, sin hacer estragos en la calle ni ofender a los transeúntes.

Entraba a su cama y dormía hasta la madrugada, feliz como una lombriz.

Iniciaba el día en la puerta del mercado San Camilo, ancha faja a la cintura y cordel al brazo. La señora Asunción Venegas aguardaba con las jabas de gallinas que Nicolás Zamalvides repartía entre las cocineras del mercado. Cumplida esta primera labor se premiaba con doble fondo de caldo de gallina que le renovaban las fuerzas para continuar la jornada hasta la tarde.

El celador del hotel lo tenía en gran estima, pues Nicolás Zamalvides era de sangre dulce, parco en hablar y en cuanto al pago de la renta era puntual como la vieja campana de Santo Domingo.

Solo que un día no amaneció, mejor dicho amaneció muerto. Hacía rato había doblado la campana de Santo Domingo y él no daba señales de vida. En vano la señora Asunción Venegas esperó con las jabas repletas de gallinas. La señora Asunción aguardó una hora, al cabo del cual llamó a un ayudante, pues parecía que Nicolás Zamalvides no acudiría, cosa por demás extraña, tratándose de un hombre que se levantaba con la aurora y que jamás había faltado a sus deberes.

--Va-dijo--habrá tenido algún problema.

La mala noticia se expandió esa misma mañana. Extrañado por la inusual demora de Nicolás Zamalvides, el celador del hotel fue en su busca con el propósito de despertarlo. Al llegar a la puerta reparó que el pestillo que daba seguridad por dentro continuaba corrido señal de que el hombre no había salido de su habitación. Entonces decidió forzarlo con una palanca de metal. Como había temido en algún momento, ante su silencio prolongado, Nicolás Zamalvides yacía muerto sobre su cama.

Fue una muerte muy sentida entre los amigos y conocidos de Nicolás Zamalvides en el mercado San Camilo y en la calle Rosada. El periodista reportó la noticia con estas palabras: "honorable caballero que trabajaba como cargador en el mercado San Camilo murió en su habitación del hotel al parecer de un infarto al corazón..."

Mientras esperaba el llamado del Señor, a mi me daba trabajo creer que hubieran transcurrido tiempos en que ocurrieron bellezas de esa naturaleza. Lo decía un periódico reputado de serio, y la nota policial no era una ficción humorística. Porque cien años después a nadie se le ocurriria llamar caballero a un cargador y mucho menos honorable, sencillamente porque esas cualidades se han desplazado a la anti- 
poda del personaje. Imposible pensar que un cargador tenga la suerte de vivir en una habitación de hotel por pobre que éste sea, y mucho menos que en las tardes disponga de su tiempo para salir de paseo vestido de terno y corbata, y menos aún que pueda acompañar con cervezas una conversación con sus amigos.

Estaba asombrado. Tal vez Nicolás Zamalvides fue un caballero afortunado que después perdió su fortuna, pero retuvo la condición de caballero, (dice la crónica que usaba terno y corbata, aunque bien sabemos que el terno y la corbata no convierten a un hombre necesariamente en caballero), y como tal seguía pensando que el trabajo, cualquiera que fuese, honraba al hombre y así no tuvo reparo en hacerse cargador. Lo de honorable quizá fue porque Nicolás Zamalvides sabía honrar su palabra y era honesto, cualidades que se pueden tener a pesar de ser cargador. De su decencia podían dar testimonio la señora Asunción Venegas, las cocineras del mercado San Camilo y el celador del hotel.

Me encontraba ensimismado tratando de entender a ese singular personaje nombrado Nicolás Zamalvides, cuando escuché una voz cavernosa como si se escapara de una catacumba. En algún momento llegué a pensar que era la voz, el llamado, en fin, que estaba esperando.

--iZamalvides, debemos cerrar la biblioteca!

Era el reverendo Juan Tamo Fernández, rector del Seminario a quien le placía llamarme por mi apellido.

No sólo me alejé del Seminario de San Jerónimo lo más que pude. Había decidido mi destino. Ya no esperaba el llamado del Señor, al menos no en esta vida. Terminé mis estudios, recibí un título que debía servir para algo. Bailé con varias muchachas y al final senté cabeza. Parte de mi oficio era viajar a los orígenes. Preguntaba a los vivos para saber de los muertos, tosía sobre libros viejísimos y acababa viajando a pequeños pueblos de la sierra incrustados en las cumbres, cerca de las estrellas.

$\mathrm{Al}$ concluir la carrera, mi profesor de historia Mario Sotillo me obsequió como recuerdo de despedida Memorias para la historia de Arequipa, del mercedario Víctor M. Barriga, en el cual se daba cuenta acerca de la vida de los pueblos del sur, de los deberes y obligaciones de sus gentes y de sus gobernantes, en las postrimerías de la Colonia, registrados por un acucioso visitador de la oficialía, con aparente propósito de enmendar las injusticias que cometían los gobernantes. Si me fijaba bien, continuaba de algún modo hablando con curas. $Y$ tal vez quise ser cura para andar metido en archivos como ratón de viejas historias, o para confesar a las monjas, que venía a ser lo mismo, porque en los archivos o en el confesonario el cura anda hurgando en la vida de los demás.

Allí me encontré otra vez con un nuevo Nicolás Zamalvides. Un poco más al sur. Un poco más lejos en el tiempo.

Seguí la probable ruta del visitador Intendente y Vicepatrón Real Teniente Coronel de los Reales Ejércitos Don Antonio Álvarez y Jiménez. Camino de herradura año cristiano de 1793. Destino Pueblo y Doctrina de San Benedicto de Abad de Tarata.

Una ruta impresionante que abarcaba el desierto y los valles yungas, siguiendo la rivera del Salado y la del Agua Dulce hasta la cabecera de Sama, donde los ojos 
del Intendente y Vicepatrón Real se regocijaron con una cascada de terrazas en pleno florecimiento.

Tras el bando y providencia que precedió a su llegada, el Intendente convocó de primera intención al alcalde ordinario de españoles Nicolás Zamalvides. Con él estuvieron el Cabildo de indios, los Segundos Mandones y Alguaciles, el indio Agustín Luque, Alcalde Mayor de naturales.

Este Nicolás Zamalvides tenía graves acusaciones en su contra, pero la más grave era haber cometido abusos en perjuicio de los indios. Empleaba sin descanso a ayllus enteros de indios en el trabajo de sus tierras de cultivo y en la fábrica de su casa. Una gran casa en el pueblo. Como corresponde a un alcalde español la suya debía ser de dos plantas y con balcón a la plaza. A los muchachos los obligaba a llevar chala para su ganado, y leña para la cocina una vez por semana. Además, ocupaba a ocho personas en su servicio permanente para cubrir sus distintas necesidades: dos pongos, dos mitanis, tres pastores de ganado y un gualpacho, este último encargado del pastoreo de gallinas. Debía tener una gran cantidad de estas aves para que un hombre se encargara exclusivamente de cuidarlas.

En su defensa, Nicolás Zamalvides dijo que no tenía más bienes que los que podía tener un español, en funciones de alcalde. En asunto de animales tenía especial predilección por las gallinas, sin que esa preferencia hiciese que descuidara vacunos, caballos, y en los bofedales de Maure, Tulipita y Viluyo ovejas y alpacas. En el pueblo y en sus alrededores cacareaban decenas de gallinas, y tras ellas corría un gualpacho. Razón tuvo el Intendente en llamarlo alcalde español de gallinas. Y no le faltaba razón, ¿cuántos españoles vivían en esa lejana villa del Señor? Aparte del propio don Nicolás Zamalvides estaba el Recaudador de Tributos; y nadie más. Otros tres que no eran indios ni españoles eran mestizos que, como todos los mestizos, no pagaban tributos.

Demás está decir que los días que estuvo el Intendente como huésped del alcalde Nicolás Zamalvides desayunaba ponche de huevo rociado con polvo de habas y tortillas de huevo, almorzaba caldo de gallina en plato hondo con tupo de plata y estofado de gallina en plato extendido, cenaba asado de gallina con papas sancochadas. La mañana que el Intendente se retiró de Tarata, el alcalde Nicolás Zamalvides ordenó a sus cocineras que llenaran las alforjas del Intendente con asados de gallina y tortillas de huevo.

Años después cuando el Intendente Antonio Álvarez y Jiménez, anciano ya y próximo a morir, quiso saber acerca de la suerte de aquél singular alcalde español de gallinas llamado Nicolás Zamalvides que conociera en la villa de San Benedicto de Abad, le avisaron que había fallecido de un ataque al corazón, un mediodía de otoño cuando regresaba de supervisar sus corrales de gallinas en los altos del ayllu Hanan Lupaja.

Ahora vivo o sobrevivo en una habitación del segundo piso a la que llego por una delgada escalera. Al girar la puerta encuentro en el piso un sobre manila en el que leo mi nombre, y de momento pienso que es un cumplido del padre Gilmer Cervantes invitándome a jugar un partido de ajedrez en su casa parroquia de Espíritu Santo. Iré de todas maneras. Aparte de tabaco, jugar ajedrez es otro vicio que he contraído 
desde los años de mi adolescencia.

El padre Gilmer prefiere invitarme por escrito y no por teléfono. Lo hace por seguridad. Cuando suena el teléfono se levanta en la casa de al lado un alboroto de gallinas que imposibilitan cualquier conversación. Digo que se levanta un gran alboroto como si las gallinas quisieran responder el teléfono. Porque el resto del día oigo su incesante cacareo y sus gritos lastimeros hacia el crepúsculo cuando el matarife selecciona una veintena y las levanta por las patas una a una para cortarles la cabeza y las condena sin piedad al caldero con agua caliente para desplumarlas. En más de una oportunidad he pensado enfrentar al propietario del criadero para evitar que las sigan torturando, pero luego me aquieto temeroso de que me trate como a un gallo $o$ quizá algo peor que eso. El tipo no tiene entrañas cuando exhibe la navaja o cuando avanza hacia el caldero humeante. Que las pobres asuman su destino, me conformo, y yo el mío. En las noches sueño, como quizás les ocurría a los otros Nicolás Zamalvides, con gallinas. No podía ser de otra manera. Cuando es tarde y hay bruma que se desenvuelve en las colinas de arena no puedo evitar asomarme a la ventana para contemplar, sin importarme el paso del tiempo, el criadero de mi vecino donde decenas de gallinas sobrevivientes se espulgan las alas.

Alguna vez he pensado poner mi propio criadero, tener una selecta clase de ponedoras como en el solar de mi infancia, pero he renunciado a esta tentación, no sé si a tiempo y vaya uno a saber si para bien o para mal. No pude ser cura, pero juego ajedrez con un cura en una casa parroquia; no crío gallinas pero vivo envuelto por su interminable cacareo. Y confieso que me siento muy bien. Un placer exquisito inunda mi alma cuando pongo en apuros al padre Gilmer con un gambito de dama, y nunca será tan grato para mis oídos que vivir rodeado, aunque no sean de mi propiedad, por esas aves que atravesaron el tiempo íntimamente ligadas a mi nombre y apellido, como si fueran parte de mi cuerpo y de mi espíritu. 